\section{Complicaciones de la otitis media en la edad pediátrica}

Complications of otitis media in pediatric age
Hugo Rolando Roca Castillo

Médico general, Hospital IESS

General de Manta,

hugo.roca693@gmail.com,

https://orcid.org/0000-0001-5162-

3265. Guayaquil, Ecuador

Carolina Rocío Bello Vinueza

Especialista en Pediatría, Hospital

IESS General de Portoviejo,

carobevi@gmail.com,

https://orcid.org/0000-0001-7636-

3674. Guayaquil, Ecuador

Xavier Oswaldo Zambrano

Montesdeoca

Magister en Investigación Clínica e

Epidemiología, Hospital IESS General

de Manta, xzambranom@hotmail.com,

https://orcid.org/0000-0001-8449-

0817. Guayaquil, Ecuador

Luis Alberto González Quiroz

Master en Alergología e Inmunología,

Desarrollo comunitario, Prefectura del

Guayas, luisgonmed-76@hotmail.com,

https://orcid.org/0000-0003-2478-

4893. Guayaquil, Ecuador

http://www.jah-

journal.com/index.php/jah

Journal of American health

Julio - Diciembre vol. 3. Num. 2 - 2020

Esta obra está bajo una Licencia

Creative Commons

Atribución-NoComercial-

CompartirIgual 4.0 Internacional.

RECIBIDO: 8 DE FEBRERO 2019

ACEPTADO: 29 DE AGOSTO 2019

PUBLICADO: 2 DE JULIO 2020

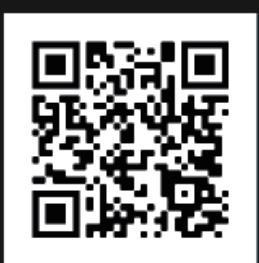

Scan this QR

code with your

smart phone or

mobile device to

read more papers

\section{RESUMEN}

La otitis media es un diagnóstico común en la población pediátrica que generalmente se maneja de forma ambulatoria. Una pequeña proporción de niños son admitidos debido a un curso complejo de la enfermedad. El objetivo de esta revisión narrativa es proporcionar una actualización sobre las complicaciones de la otitis media en niños. Se utilizó PUBMED como motor de búsqueda sistemática de información de artículos de revisión de la literatura, guías de manejo y de análisis de datos. Se incluyeron 22 artículos científicos del año 2010 al 2019. Conclusión: La otitis media aguda se diagnostica con base en la visualización de una membrana timpánica llena o abultada con derrame del oído medio. El cuadro clínico y el tratamiento de la otitis media aguda y sus complicaciones han cambiado durante las últimas décadas. La disponibilidad de antibióticos ha disminuido significativamente la incidencia de complicaciones.

PALABRAS CLAVE: otitis media, complicaciones, mastoiditis, absceso subperióstico.

\section{ABSTRACT}

Otitis media is a common diagnosis in the pediatric population that is generally managed on an outpatient basis. A small proportion of children are admitted due to a complex course of the disease. The objective of this narrative review is to provide an update on the complications of otitis media in children. PUBMED was used as a systematic search engine for information from literature review articles, management guides and data analysis. 22 scientific articles from 2010 to 2019 were included and meta-analyzes were excluded. Conclusion: Acute otitis media is diagnosed 
based on visualization of a full or bulky tympanic membrane with effusion of the middle ear. The clinical picture and treatment of acute otitis media and its complications have changed in recent decades. The availability of antibiotics has significantly decreased the incidence of complications.

\section{INTRODUCCIÓN}

La otitis media (OM) pediátrica es una de las afecciones más comunes tratadas en clínicas de atención primaria y se asocia con costos de atención médica significativos, especialmente en pacientes de 1 a 3 años (1,2). Si bien la mayoría de los casos de OM no son complicados y se tratan de forma ambulatoria, una pequeña proporción de pacientes desarrolla complicaciones que requieren ingreso hospitalario y ocasionalmente, intervención quirúrgica. Varios estudios de una sola institución han descrito la incidencia y los resultados de la OM complicada; sin embargo, la caracterización de poblaciones específicas de pacientes en riesgo y los costos de atención médica asociados con la OM complicada han sido limitados.

Constituye un grupo de afecciones infecciosas e inflamatorias complejas que afectan el oído medio, con una variedad de subtipos que difieren en presentación, complicaciones asociadas y tratamiento. Además, es una de las principales causas de visitas de atención médica en todo el mundo, y sus complicaciones son causas importantes de pérdida auditiva prevenible, particularmente en el mundo en desarrollo. Se estima que entre el $50 \%$ y el $85 \%$ de los niños experimentan al menos un episodio de otitis media agudas (OMA) a los 3 años de edad, con una incidencia máxima de entre 6 y 15 meses (3). La OMA es la causa más común de discapacidad auditiva en niños en el mundo y puede afectar hasta el $80 \%$ de los niños en algún momento, con aproximadamente 2.2 millones de nuevos casos anualmente en los Estados Unidos (4).

Los niños pequeños son más propensos a OM aguda y crónica debido a una predisposición anatómica (1); La trompa de Eustaquio es más corta, más flexible y horizontal, lo que permite que los patógenos nasofaríngeos ingresen al oído medio con relativa facilidad (3). De hecho, se ha demostrado que las dimensiones nasofaríngeas son más pequeñas en niños que sufren ataques repetidos de OMA. La trompa de Eustaquio madura a los 7 años (4); Esto puede explicar la disminución relativa de la incidencia de la patología después de esta edad. La inmadurez del sistema inmune también puede ser un factor que contribuye a la OMA.

La introducción de antibióticos e inmunizaciones durante el siglo XX condujo a una disminución dramática en la morbilidad y mortalidad relacionadas con la otitis media supurativa aguda y crónica. Durante los últimos 50 años, el aumento en el bienestar social y el acceso a la atención 
médica ha mejorado la atención médica para todos los pacientes (2). Estas medidas han llevado a una disminución de 10 veces en la mortalidad por complicaciones relacionadas con la otitis media. A pesar de esta disminución, los informes de complicaciones graves continúan en todo el mundo y la resistencia bacteriana emergente a los antibióticos está implicada en la creciente incidencia de complicaciones en algunos casos.

Este artículo proporciona una actualización sobre las principales complicaciones de la otitis media en la edad pediátrica basada en la recopilación de información de articulos de revisión y metaanálisis. Se espera profundizar la comprensión de las vías fisiopatológicas involucradas en el desarrollo de complicaciones con la finalidad de promover estrategias de prevención.

\section{MATERIALES Y MÉTODOS}

Se revisó sistemáticamente la literatura publicada en Pubmed del 1 de enero del 2010 al 31 de diciembre del 2019 para seleccionar de articulos de revisión de la literatura y guías de manejo. Se incluyeron 12 articulos científicos de revisión y 5 artículos de análisis de datos, incluidos los metaanálisis. Además, se excluyeron articulos de investigaciones originales y metaanálisis que trataban de tratamiento. Las variables evaluadas fueron: complicaciones, signos de peligro, mastoiditis, absceso subperióstico, absceso de Bezold, absceso de Luc y cigomatitis. La estrategia de búsqueda fue empleando palabras clave mediante los Medical Subject Headings (MeSH) de Pubmed.

\section{RESULTADOS}

Aproximadamente del $90 \%$ al $95 \%$ de los casos de otitis media aguda (OMA) y otitis media con derrame (OMD) están precedidos por una infección de las vías respiratorias (IVR) viral $(1,2)$. La alergia a las vías aéreas superiores puede causar disfunción de la trompa de Eustaquio y provocar OMD y con mucha menos frecuencia una OMA (3). La precede y sigue a la AOM. Este concepto es bastante nuevo. A la mayoría de los proveedores de atención médica se les enseñó que la OMD sigue a la OMA, pero no que la OMD también precede a la OMA (4). La IVR viral prepara el escenario para la OMA y la OMD al aumentar la producción de moco, relentizar el latido de los cilios en la región nasofaríngea, crear inflamación nasofaríngea y regular a la baja la respuesta inmune innata y adaptativa. Luego, la trompa de Eustaquio se cierra debido a la inflamación que se produce como parte del proceso viral de la infección del tracto respiratorio (5).

La presión negativa se acumula en el espacio del oído medio, lo que resulta en una membrana timpánica retraída. La distorsión de la membrana timpánica causada por la retracción puede confundirse fácilmente con abultamiento (3). El oído medio también produce moco para mantener húmeda la superficie de las células del oído medio. Con la trompa de Eustaquio cerrada, el moco se acumula y hace que el líquido sea visible detrás de la membrana timpánica $(4,5)$; Esto es OMD. Sin embargo, cuando se desarrolla la OMD, el oído medio todavía es estéril 
y la ausencia de un virus o una bacteria hace que la membrana timpánica permanezca generalmente translúcida.

Las secreciones en la región nasofaríngea son absorbidas literalmente en el espacio del oído medio cuando la trompa de Eustaquio se relaja temporalmente durante una parte de un segundo. Una vez que las secreciones, el virus y las bacterias acompañantes que estaban en la región nasofaríngea ingresan al espacio del oído medio, el ambiente está libre de factores de control inmunitario y las bacterias comienzan a dividirse $(1,3)$. En respuesta a la invasión local de bacterias, se activa la respuesta inmune innata, lo que resulta en la afluencia de neutrófilos. Los neutrófilos liberan mediadores de la inflamación, y el proveedor de atención médica observa ese proceso patogénico al vislumbrar la membrana timpánica que se ha engrosado con edema, quizás eritematosa, pero lo más importante observa el abultamiento de la presión de una respuesta inflamatoria $(2,4,5)$.

\section{Complicaciones}

Las complicaciones se clasifican por ubicación, ya que la enfermedad se propaga más allá de las estructuras mucosas de la hendidura del oído medio. Se pueden clasificar de la siguiente manera $(4,5,6)$ :

- Intratemporal: perforación de la membrana timpánica, mastoiditis coalescente aguda, parálisis del nervio facial, laberintitis aguda, petrositis, otitis necrótica aguda o desarrollo de otitis media crónica.

- Intracraneal: meningitis, encefalitis, absceso cerebral, otitis hidrocefalia, absceso subaracnoideo, absceso subdural o trombosis sinusal sigmoidea

- Sistémicas: bacteriemia, artritis séptica o endocarditis bacteriana.

Los signos de peligro de posibles complicaciones inminentes incluyen (a) flacidez de la pared del canal posterior, (b) sequedad de la región atical y (c) edema de las áreas postauriculares con pérdida del pliegue de la piel. La aparición de complicaciones intracraneales o intratemporales es poco frecuente, y suele asociarse a procesos de otitis crónica colesteatomatosa (6).

Las complicaciones intracraneales pueden ser explicadas por la propagación de la infección del oído a la cavidad craneal por diferentes vías: Por contigüidad: es la forma más habitual y está causada por un proceso de erosión y osteítis que llega hasta el sistema nervioso central. Ya sea un cuadro infeccioso o un colesteatoma que va erosionando las paredes óseas, la infección llega hasta la duramadre. Por continuidad: es decir, a través de vías ya preformadas: el canal del facial, los conductillos carotidotimpánicos, las suturas óseas, etc. Vía laberíntica: ésta es la vía más frecuente por la que se producen los cuadros meningíticos. La infección del laberinto pasa al canal auditivo interno y luego al endocráneo. Una posibilidad extraña, pero posible, sería la extensión a través del acueducto del vestíbulo, el saco endolinfático y el acueducto coclear. Vía hemática: a través de vasos emisarios que atraviesan tabiques óseos y otras barreras fisiológicas $(6,7)$.

Pérdida de la audición 
El oído medio es integral en la transmisión acústica del sonido y el habla del mundo externo a la cóclea. Los tipos de pérdida auditiva incluyen patrones conductivos, sensoriales, neurales y mixtos (6). La pérdida auditiva conductiva implica la interferencia de la transmisión del sonido a la cóclea, la pérdida auditiva sensorial implica la disfunción de las células ciliadas dentro de la cóclea y la pérdida auditiva neuronal generalmente ocurre con la disfunción del nervio auditivo (7). La pérdida auditiva sensorial y neural a menudo se combina como pérdida auditiva neurosensorial. La acumulación de líquido e inflamación en la OM casi siempre incluirá un componente de pérdida auditiva conductiva (8). Si bien una pérdida auditiva temporal leve en un niño mayor o en un adulto es intrascendente, una discapacidad auditiva conductiva leve a moderada en un niño más pequeño puede ser significativa, ya que los primeros 2-3 años de vida se consideran un período crítico para el habla y el desarrollo del lenguaje.

\section{Mastoiditis}

La mastoiditis aguda fue la complicación más común de la otitis media aguda antes del advenimiento de los antibióticos. A pesar de la disminución significativa de la morbilidad y la mortalidad, la mastoiditis aguda sigue siendo una complicación grave que hace que el frío avance hacia complicaciones intracraneales potencialmente mortales (7). La mastoiditis aguda podría presentarse en dos formas clínicas: forma no coalescente y coalescente. El engrosamiento inflamatorio de la capa mucoperióstica en el antro mastoideo y el complejo celular caracteriza la mastoiditis no coalescente, mientras que la forma coalescente progresa hacia la destrucción de las paredes óseas del proceso mastoideo $(8,9)$. Las bacterias virulentas y la respuesta inmunitaria disminuida son los factores más comunes que conducen a la progresión intracraneal de la infección y la gran variedad de complicaciones intracraneales, como meningitis purulenta, trombosis del seno lateral y absceso intracraneal.

Parálisis facial

La parálisis del nervio facial es una complicación poco común pero grave de la OM con consecuencias devastadoras funcional, estética y emocionalmente. Si bien la incidencia de la parálisis del nervio facial ha disminuido significativamente desde la era previa a los antibióticos, donde ocurrió en hasta 2 de cada 100 casos de OM a aproximadamente 1 en 2000 en la era posterior a los antibióticos, la prevención y el tratamiento pueden ser un problema difícil $(8,9)$. La parálisis facial puede ser el resultado de una OMA o una otitis media crónica (OMC) con o sin colesteatoma (epitelio escamoso atrapado en el oído medio o mastoideo). En los niños, la parálisis facial se observa con mayor frecuencia en la OMA, mientras que, en los adultos, la causa más probable es la OMC en 1 a $3 \%$ de los pacientes con parálisis facial (10).

La etiología de la parálisis del nervio facial en la OM no se conoce bien, pero los posibles mecanismos incluyen efectos neurotóxicos directos, inflamación y edema del nervio e isquemia (2). En la OMC, la parálisis facial se atribuye a la erosión del canal óseo por infección o por 
colesteatoma que comprime el nervio. El diagnóstico de la parálisis facial se realiza mediante un examen físico. Todas las ramas del nervio facial se verán afectadas (10).

Absceso subperióstico.

Es la forma de evolución más frecuente de la mastoiditis aguda. El absceso se localiza en la cortical mastoidea y se traduce como una tumefacción fluctuante retroauricular con un despegamiento significativo del pabellón hacia delante, abajo y afuera. El dolor ante la palpación es intenso. El tratamiento, siguiendo la máxima de ibi pus ubi vacue, es el drenaje quirúrgico (10).

\section{Absceso de Bezold}

Como hemos comentado con anterioridad, se produce en mastoides muy neumatizadas en las que la infección se escapa por la punta mastoidea hacia espacios cervicales inferiores. La tumefacción es de localización laterocervical, ipsolateral al proceso ótico, y requiere tratamiento quirúrgico urgente (10).

\section{Absceso de Duhnn-Mouret}

Existe una implicación digástrica con una posible extensión hacia espacios retrofaríngeos (10).

\section{Absceso de Luc}

Se produce por una extensión a lo largo de la cortical del CAE y la apertura posterior a la luz. Puede confundirse con una otitis externa abscesificada, pero tanto la función auditiva como las pruebas de imagen proporcionarán su confirmación (10).

\section{Cigomatitis}

También hemos apuntado esta posibilidad con anterioridad. Un cigoma neumatizado transportará la infección hacia la articulación témporo-mandibular (ATM) y la región facial (10).

\section{Petrositis - Síndrome de Gradenigo}

La petrositis es similar a la mastoiditis, pero involucra un área diferente dentro del hueso temporal. Fue descrito por primera vez en 1904 por Giuseppe Gradenigo como una tríada de dolor periorbitario unilateral, diplopía de la parálisis de abducens a medida que el nervio pasa a través del canal de Dorello y otorrea causada por una OM bacteriana con afectación de la porción petrosa del hueso temporal (apicitis petrosa) (7,9). La tomografía computarizada del hueso temporal con contraste es la modalidad de imagen elegida para correlacionarse con los síntomas clínicos en el diagnóstico de petrositis. El tratamiento inicial es similar al de otras complicaciones intratemporales de $\mathrm{OM}$ con el inicio de antibióticos de amplio espectro. Este síndrome es raro; complica menos del $2 \%$ de la otitis media aguda, sean o no tratados con 
antibióticos (10). Sus síntomas se explican por la extensión de la infección del oído medio al antro mastoideo y luego al ápice petroso a través de las células mastoides neumáticas.

\section{DISCUSIÓN}

La presentación de síntomas en niños con complicaciones de la OMA puede variar, lo que significa que debe haber un mayor grado de sospecha presente para establecer el diagnóstico (1). La otalgia y dolor postauricular han sido reportados como los síntomas más comunes de complicaciones intratemporales (5). En un gran estudio, se encontró fiebre mayor a $38.38 \mathrm{C}$ en el $70.8 \%$ de los pacientes con mastoiditis aguda, pero solo en el $18.2 \%$ de los pacientes con parálisis facial aguda (11). Otro estudio encontró que el $61,5 \%$ de los pacientes que presentaban trombosis sinusal lateral presentaban fiebre. Se ha descubierto que la obtención de imágenes con CT del hueso temporal con contraste intravenoso es una prueba diagnóstica altamente sensible (sensibilidad del 97\%) para evaluar las complicaciones de la OMA (12).

No debemos confundir una mastoiditis con una adenopatía retroauricular inflamada en el contexto de una otitis, lo cual no es infrecuente. Una palpación cuidadosa, el contexto clínico e incluso las pruebas de imagen nos permitirán diferenciarlo. En adolescentes e incluso en adultos, la sobreinfección de un quiste sebáceo retroauricular proporcionará una imagen de absceso, fluctuación y dolor, pero la ausencia de afección ótica asociada nos sacará de dudas. Una furunculosis del conducto auditivo externo (CAE) puede producir una tumefacción de la porción cartilaginosa del conducto, pero no el hundimiento de la pared posterosuperior. De manera adicional, el tímpano y la caja no necesariamente resultarán afectadas en las enfermedades exclusivas del CAE. La cigomatitis puede confundirse fácilmente con una parotiditis $(3,9)$. El contexto clínico, la otoscopia y las pruebas de imagen serán de gran utilidad en estos casos poco frecuentes.

En la actualidad la mastoiditis pediátrica es una complicación rara de la OMA, en un estudio de King et al que encontró que, a nivel nacional en los Estados Unidos, entre 2000 y 2012, la incidencia estimada de mastoiditis pediátrica alcanzó su punto máximo en 2006, con 2,7 casos por cada 100,000 habitantes y cayó a su punto más bajo en 2012, en 1.8 casos por 100,000 habitantes (13). Un estudio de 177 niños de 6 meses a 7 años sugirió que los episodios recurrentes de OMA aumentan el riesgo de perforación espontánea de la membrana timpánica (PEMT) (14). Además, el estudio, realizado por Marchisio et al, encontró una alta frecuencia (50.8\%) de $H$ influenzae no tipificable en el líquido del oído medio de pacientes con OMA con PEMT, particularmente en aquellos con casos recurrentes. Los $M$. catarrhalis y $S$. pneumoniae ( $35.0 \%$ y $27.1 \%$ de los casos, respectivamente) fueron los siguientes patógenos bacterianos más comunes encontrados en la OMA con PEMT (8). 


\section{CONCLUSIONES}

La otitis media aguda se diagnostica con base en la visualización de una membrana timpánica Ilena o abultada con derrame del oído medio. El cuadro clínico y el tratamiento de la otitis media aguda y sus complicaciones han cambiado durante las últimas décadas. La disponibilidad de antibióticos ha disminuido significativamente la incidencia de complicaciones y aunque son poco frecuentes, continúan teniendo consecuencias potencialmente graves.

La etiología bacteriana más común sigue siendo el Streptococcus pneumoniae. Sin embargo, parece haber una tendencia creciente de organismos resistentes en este proceso de enfermedad, con el $55 \%$ de las cepas que muestran resistencia en la población infantil. Los médicos deben estar al tanto de la presentación y el manejo de estas complicaciones, además, del monitoreo continuo de la bacteriología.

El tratamiento quirúrgico es predominantemente necesario para las complicaciones intracraneales y los abscesos intratemporales. Las complicaciones de la OM todavía se asocian con una morbilidad considerable, y es muy probable que el reconocimiento temprano forme la base para un tratamiento efectivo.

\section{REFERENCIAS}

1. Lavin J. Complications of Pediatric Otitis Media. Otolaryngol Head Neck Surg. Vol. 154(2):366-370. doi:10.1177/0194599815611860. 2016.

2. Pichichero M. Otitis media. Pediatr Clin North Am. Vol. 60(2):391-407. doi:10.1016/j.pcl.2012.12.007. 2013.

3. Leung A. Acute Otitis Media in Children. Recent Pat Inflamm Allergy Drug Discov. Vol. 11(1):32-40. doi:10.2174/1874609810666170712145332. 2017.

4. Hutz M. Neurological Complications of Acute and Chronic Otitis Media. Curr Neurol Neurosci Rep. Vol. 18(3):11. Published 2018 Feb 14. doi:10.1007/s11910-018-0817-7. 2018.

5. Danishyar A. Otitis media aguda. En: StatPearls [Internet]. Treasure Island (FL): StatPearls Publishing; Disponible en: https://www.ncbi.nlm.nih.gov/books/NBK470332/. 2019.

6. Qureishi A. Update on otitis media - prevention and treatment. Infect Drug Resist. Vol. 7 (1):15-24. doi:10.2147/IDR.S39637. 2014.

7. Adhami M. Complications of acute otitis media in children: case reports and review of literature. J Med Liban. Vol. 58(4):231-237. 2010.

8. Marchisio et al. Prospective evaluation of the aetiology of acute otitis media with spontaneous tympanic membrane perforation. Clin Microbiol Infect. 2017 Jan 19. 2017.

9. Mattos J. Intratemporal and intracranial complications of acute otitis media in a pediatric population. Int J Pediatr Otorhinolaryngol. Vol. 78(12):2161-2164. doi:10.1016/j.ijporl.2014.09.032. 2014. 
10. Wanna G. Contemporary management of intracranial complications of otitis media. Otol Neurotol. Vol. 31(1):111-117. doi:10.1097/MAO.0b013e3181c2a0a8. 2010.

11. Venekamp R. Acute otitis media in children. BMJ Clin Evid. 2014:0301. 2014.

12. Monasta et al. Burden of disease caused by otitis media: systematic review and global estimates. PLoS One. Vol. 7(4):e36226.. 2012.

13. King et al. National Incidence of Pediatric Mastoiditis in the United States, 2000-2012: Creating a Baseline for Public Health Surveillance. Pediatr Infect Dis J.. 2018.

14. Li et al. Panel 4: Recent advances in otitis media in molecular biology, biochemistry, genetics, and animal models. Otolaryngol Head Neck Surg. Vol. 148(4 Suppl):E52-E63. doi:10.1177/0194599813479772. 2013. 